\title{
Tireoidite supurativa aguda com múltiplas complicações
}

\author{
Acute suppurative thyroiditis with multiple complications
}

Izabela Fernandes Alves da Fonseca', Cristina Kayat Avvad ${ }^{2}$, Eduardo Guilherme Sanchez ${ }^{3}$, Jodélia Lima Martins Henriques ${ }^{4}$, Lenora M. Camarate S. M. Leão4

\footnotetext{
1 Programa de Especialização Lato Sensu em Endocrinologia, Diabetes e Metabologia, Faculdade de Ciências Médicas, Universidade do Estado do Rio de Janeiro (UERJ), Rio de Janeiro, RJ, Brasi 2 Disciplina de Endocrinologia, Universidade do Grande Rio (Unigranrio), Rio de Janeiro, RJ, Brasil

${ }^{3}$ Serviço de Endocrinologia, Hospital Quinta D'Or, Rio de Janeiro, RJ, Brasil

${ }^{4}$ Serviço de Endocrinologia UERJ, Rio de Janeiro, RJ, Brasil
}

Correspondência para: Izabela Fernandes Alves da Fonseca Rua Van Gogh, 303

20771-480 - Rio de Janeiro, RJ, Brasil izabela fonseca@ig combr

izabelafafonseca@gmail.com

Recebido em 23/Dez/2011 Aceito em 19/Jun/2012

\section{SUMÁRIO}

A tireoidite supurativa aguda é uma desordem rara, mais frequentemente causada pelo Staphylococcus aureus ou Streptococcus pneumoniae, e atinge particularmente crianças com fístula do seio piriforme. Em adultos, a disseminação por via hematogênica a partir de foco infeccioso em orofaringe ou trato respiratório parece ser o principal mecanismo patogênico. Os sinais e sintomas iniciais da tireoidite aguda são semelhantes aos da faringite aguda e da tireoidite subaguda. Esse fato frequentemente retarda o diagnóstico dessa doença e aumenta o risco de complicações. Relatamos o caso de um paciente masculino de 28 anos, previamente saudável, que, após quadro de amigdalite, apresentou tireoidite aguda complicada por tireotoxicose, volumoso abscesso no lobo direito da tireoide, que se estendia à abertura superior do tórax com desvio da traqueia e compressão de grandes vasos, associado à trombose de veia jugular interna e sepse. Arq Bras Endocrinol Metab. 2012;56(6):388-92

\section{SUMMARY}

Acute suppurative thyroiditis is a rare disorder, most often caused by Staphylococcus aureus or Streptococcus pneumoniae, which affects particularly children with pyriform sinus fistula. In adults, the main pathogenic mechanism seems to be hematogenous dissemination from a focus of infection in the oropharynx or respiratory tract. The initial signs and symptoms of acute thyroiditis are similar to those of acute pharyngitis and subacute thyroiditis. This fact often delays diagnosis and increases the risk of complications. We report the case of a previously healthy, 28-year-old man who, after being affected by tonsillitis, developed suppurative thyroiditis complicated by thyrotoxicosis; a large abscess in the right lobe of the thyroid extending to the thorax introitus, which caused a trachea deviation and compressed large vessels; associated with internal jugular vein thrombosis, and sepsis. Arq Bras Endocrinol Metab. 2012;56(6):388-92

\section{INTRODUÇÃO}

$\mathrm{D}$ escrita inicialmente por Bauchet em 1857 e Robertson em 1911, a tireoidite supurativa aguda (TA) é uma doença rara, porém de alta morbidade e mortalidade caso não seja prontamente reconhecida e tratada. A TA acomete ambos os sexos e todas as idades, sendo mais prevalente em crianças com alterações anatômicas congênitas, tais como a fístula do seio piriforme (1-4). Foram também descritos casos relacionados à persistência do ducto tireoglosso, infecção por contiguidade (laceração esofágica por corpo estranho, traumatismo, neoplasia), complicações de procedimentos diagnósticos ou terapêuticos (punções, cirurgias), disseminação por via linfática e principalmente por via hematogênica a partir de um foco na pele, trato respiratório, gastrointestinal ou geniturinário $(2,3,5)$. Um aumento na prevalência de TA foi observado nas últimas décadas possivelmente devido à elevação do número de pacientes imunocomprometidos (3).

Os agentes etiológicos mais frequentemente vinculados à TA são as bactérias Gram-positivas, como o Staphylococcus aureus e o Streptococcus pneumoniae. 
Entretanto, os bacilos Gram-negativos, Klebsiella spp., Haemophilus influenzae, Streptococcus viridans, Salmonella spp., Mycobacterium tuberculosis e fungos (Coccidioides immitis, Aspergillus, Actinomyces, Acinetobacter calcoaceticus e cândida) também foram identificados como agentes causais, particularmente em indivíduos portadores de imunodeficiência $(2-4,6)$.

As manifestações clínicas podem ser agudas ou desenvolver-se gradualmente simulando o quadro de faringite, amigdalite ou tireoidite subaguda. Os sinais e sintomas costumam ser mais evidentes em crianças, manifestando-se classicamente por febre alta, calafrios, astenia, dor na região cervical anterior, aumento assimétrico do volume tireoidiano com palpação extremamente dolorosa e linfonodomegalia cervical $(3,7)$. O diagnóstico é sugerido por métodos de imagem que incluem ultrassonografia (US) e tomografia computadorizada (TC). À US observam-se edema unilobular e/ou formação de abscesso, já a TC é particularmente importante para avaliação das estruturas vizinhas (7).

Tradicionalmente, a abordagem terapêutica inclui terapia antimicrobiana prolongada associada à drenagem cirúrgica ou, em alguns casos, tireoidectomia parcial ou total $(8,9)$. A escolha do esquema de antibióticos fundamenta-se nos resultados da bacterioscopia pelo método de Gram e cultura do material aspirado por punção ou drenagem cirúrgica, devendo ser iniciado antes da obtenção desses resultados, de forma empírica, com antibióticos de amplo espectro cobrindo especialmente os cocos Gram-positivos (1-3,10).

De fato, a tireoidite piogênica está vinculada a complicações raras que incluem disfunções hormonais (hipotireoidismo ou tireotoxicose), abscesso de tireoide, compressão da traqueia, abscessos cervical e mediastinal, tromboflebite de veia jugular interna e sepse (11).

\section{RELATO DO CASO}

R.M.G., 28 anos, sexo masculino, procurou o serviço de emergência do Hospital Quinta D'or com queixa de odinofagia, mialgia e episódios de febre não associados a sintomas respiratórios. Relatava quadro de amigdalite há 10 dias, tratada com prednisolona por 3 dias e amoxicilina sem melhora significativa dos sintomas. $\mathrm{Na}$ história patológica pregressa, não havia nada digno de nota. Negava qualquer alteração anatômica ou funcional de tireoide ou história familiar de tireoidopatia. No exame físico, apresentava-se corado, hidratado, afebril, eupneico e normotenso, com frequência cardíaca de 96 bpm e aumento de volume do lobo direito da tireoide, doloroso à palpação e móvel à deglutição. Havia leve hiperemia de orofaringe posterior. Exames laboratoriais mostraram: leucócitos $=18.550 / \mathrm{mm}^{3}(3.500$ $11.300)$ com aumento de bastões (13\%); VHS $=28$ $\mathrm{mm} / \mathrm{h}(0-10) ; \mathrm{TSH}=0,0 \mathrm{luU} / \mathrm{mL}(0,3-5,0)$ e T4 livre $=7,77 \mathrm{ng} / \mathrm{dL}(0,8-1,9)$. No ecoDoppler de tireoide demonstrava-se aumento de volume do lobo direito, difusamente heterogêneo sem aumento de fluxo intraparenquimatoso. Foi feita a hipótese diagnóstica de tireoidite subaguda e o paciente recebeu alta em uso de sintomáticos com a orientação de retornar ao setor de Endocrinologia no dia seguinte para reavaliação da função tireoidiana e tratamento.

$\mathrm{O}$ paciente não procurou endocrinologista e retornou à emergência seis dias após, referindo, então, febre alta diária, dor de forte intensidade na topografia de tireoide, odinofagia e disfagia. Ao exame físico, apresentava-se em regular estado geral, corado, hidratado, acianótico, anictérico, taquicárdico (FC: $141 \mathrm{bpm})$, febril $\left(\mathrm{Tax}=39^{\circ} \mathrm{C}\right)$. A tireoide estava aumentada de forma difusa principalmente às custas de lobo direito, sendo muito dolorosa à palpação superficial com superfície irregular, consistência elástica sem nódulos ou adenomegalias cervicais palpáveis. Exames laboratoriais mostraram leucócitos $=17.170$ leucócitos $/ \mathrm{uL}$ com $10 \%$ de bastões; VHS = $95 \mathrm{~mm} / \mathrm{h}$; PCR $=15,8 \mathrm{mg} / \mathrm{dL}$ (até 1,0); anti-TPO = $27 \mathrm{UI} / \mathrm{mL}$ (até 34) e anti-HIV negativo. As radiografias de tórax e seios da face eram normais. A US confirmou aumento importante do volume tireoidiano com glândula de contornos lobulados e indefinidos, ecotextura grosseiramente heterogênea (principalmente em lobo direito) com aspecto pseudonodular, sugerindo-se a presença de coleção líquida. O mapeamento com Doppler colorido mostrou parênquima glandular pobremente vascularizado.

Considerando-se a hipótese diagnóstica de TA, o paciente foi internado para analgesia, punção e antibioticoterapia, sendo inicialmente tratado com amoxicilina e clavulanato. No segundo dia de internação hospitalar, evoluiu com quadro de sepse, apresentando taquicardia (FC: $140 \mathrm{bpm}$ ), taquipneia (FR: $28 \mathrm{irpm}$ ), febre (Tax: $40^{\circ} \mathrm{C}$ ), desconforto respiratório, aumento do volume cervical e agravamento da leucocitose (24.820 leucócitos/uL), sendo transferido para o Centro de Terapia Intensiva (CTI), onde realizou imediatamente TC de pescoço (Figura 1). A TC mostrou tireoide com dimensões aumentadas e limites mal definidos, apresentando volumosa coleção líquida acometendo o lobo direito, que media $4,9 \times 3,8 \times 4,2 \mathrm{~cm}$, com volume estimado em $41 \mathrm{~mL}$ (vr: aproximadamente $20 \mathrm{~mL}$ ), com- 


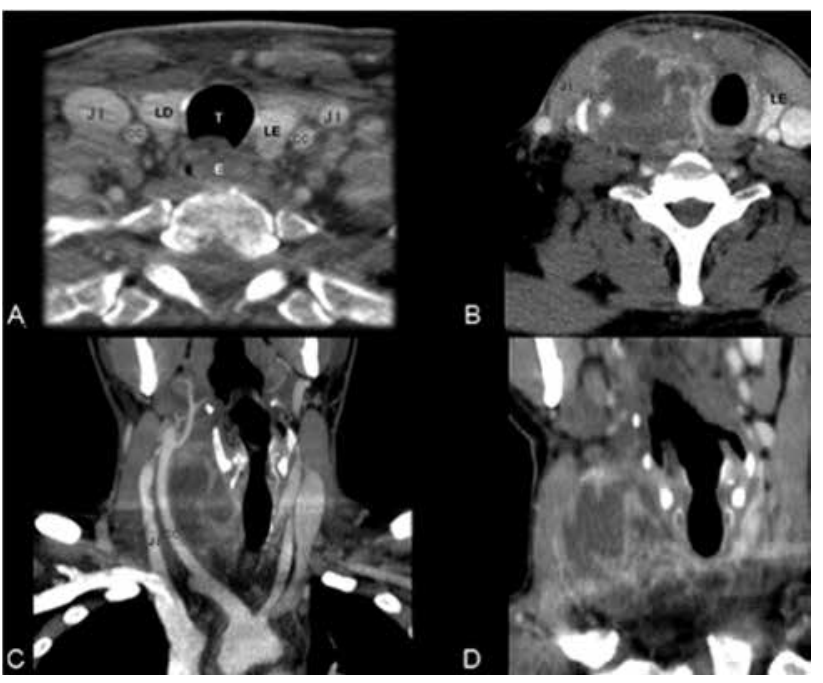

Figura 1. Exame tomográfico do pescoço. Exame normal para comparação (A). Aquisição axial (B) e coronal (C e D), mostrando volumosa coleção do lobo direito (LD) que rechaça a carótida comum (CC) e comprime veia jugular interna (JI) homolateral e estende-se ao introito torácico. Nota-se também deslocamento da traqueia (T) para a esquerda. E: esôfago; LE: lobo esquerdo.

primindo a carótida comum e a veia jugular comum à direita, deslocando a traqueia para a esquerda e estendendo-se ao introito torácico. A imagem era compatível com TA associada a abscesso tireoidiano com efeitos compressivos. Após procedimento de intubação orotraqueal, foi realizada a drenagem do abscesso cervical com colocação de dreno, sendo instituído novo esquema terapêutico que associava ticarcilina, clavulanato e metronidazol, para maior cobertura antibiótica, até que os resultados da cultura do material estivessem disponíveis.

No segundo dia de internação no CTI, apresentava-se dependente de ventilação mecânica e vasopressores. Leucócitos $=30.400$ leucócitos $/ \mathrm{uL} ; \mathrm{T} 4$ livre $=2,30 \mathrm{ng} /$ $\mathrm{dL} ; \mathrm{TSH}=0,03 \mathrm{uUI} / \mathrm{mL} ; \mathrm{PCR}=20,30 \mathrm{mg} / \mathrm{dL}$. A hemocultura e a urinocultura foram negativas. A cultura do material aspirado detectou a presença isolada do Streptococcus beta bemolitico. O metronidazol foi substituído por clindamicina, de acordo com o resultado do antibiograma, e, considerando-se a importante redução dos níveis séricos de tiroxina, optou-se pela monitorização dos níveis hormonais, não sendo introduzida droga antitireoidiana para controle da tireotoxicose.

No terceiro dia de internação no CTI, houve melhora do quadro clínico e laboratorial. A TC de controle mostrava redução do volume tireoideo, ausência de coleção líquida ou compressão de grandes vasos. Recebeu alta do CTI após oito dias, sendo mantido em antibioticoterapia e acompanhamento hospitalar. Após 11 dias de internação,

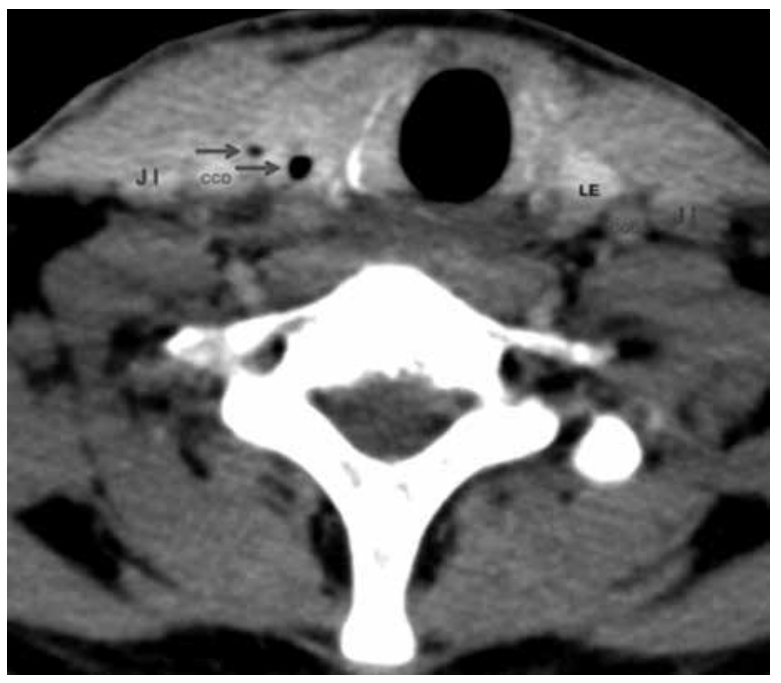

Figura 2. Estudo tomográfico. Observa-se espessamento parietal da carótida comum direita (CCD), de provável natureza reacional. Gás de permeio (setas). LE: Iobo esquerdo; Jl: jugular interna; CCE: carótida comum esquerda.

o paciente apresentava-se sem sinais flogísticos locais, com discreta odinofagia, sendo retirado o dreno percutâneo da região cervical. Os níveis séricos de TSH e T4 livre encontravam-se normais. A TC de pescoço (Figura 2) mostrou área com densidade heterogênea na região paratraqueal direita, predominantemente hiperdensa com gás de permeio e perda/distorção da arquitetura habitual do lobo direito da tireoide. Na US identificou-se pequeno trombo periférico em veia jugular interna e foi iniciada anticoagulação com heparina 40 UI subcutânea.

Recebeu alta hospitalar após 12 dias de internação, assintomático, com prescrição domiciliar de antibióticos e heparina de baixo peso molecular na dose de $80 \mathrm{mg} /$ dia.

\section{DISCUSSÃO}

Al-Dajani e Wootton (10) estimam que a TA represente apenas $0,1 \%$ a $0,7 \%$ de todas as doenças da tireoide. De fato, tomando-se por base dois extensos levantamentos da literatura médica realizados na última década (12), a doença é bastante incomum, tendo sido descritas, desde 1900, somente cerca de seis centenas de casos. As infecções supurativas na tireoide são eventos clínicos raros porque a glândula não apresenta comunicação direta com o meio externo e, adicionalmente, é protegida por uma cápsula espessa, possui amplo suprimento sanguíneo e drenagem linfática, além de altas concentrações parenquimatosas de iodo e de peróxido 
de hidrogênio, os quais possuem propriedades bactericidas $(2,3,7)$.

Defeitos congênitos que favoreçam a comunicação entre o parênquima tireoidiano e a faringe (mais frequentemente a fístula do seio piriforme) são a causa mais comum de TA, devendo ser suspeitados em todos os casos de TA diagnosticados em crianças, particularmente naquelas com comprometimento do lobo esquerdo, e em adultos com recidiva da doença (13). Nos adultos, a disseminação da infecção por via hematogênica, a partir do trato respiratório, faringe ou ouvido médio, tem sido considerada o principal meio de contaminação da tireoide, embora nem sempre o foco primário possa ser identificado (12).

Relatamos o caso raro de um homem jovem, previamente hígido, sem comprometimento do sistema imune (excluídos HIV, diabete melito, realização de transplantes e quimioterapia), que apresentou quadro de TA comprometendo especialmente o lobo direito da tireoide associado a múltiplas complicações. A faixa etária do paciente, o comprometimento preferencial do lobo direito da glândula, a história recente de amigdalite/faringite e a identificação de Streptococcus beta bemolítico como agente etiológico sugerem que a contaminação ocorreu por via hematogênica a partir de um foco em orofaringe. De fato, o Streptococcus beta hemolitico e o Staphylococcus aureus são os principais responsáveis por septicemia após amigdalite e, desde revisão de 1955, permanecem como os mais frequentes agentes causais de TA (14). A prevalência de abscessos tireoidianos causados por Salmonellas, anaeróbios e Mycobacterium tuberculosis decresceu acentuadamente no último século e outros agentes oportunistas, tais como o Cryptococcus, cytomegalovirus e Pneumocystis carinii, são descritos apenas em pacientes imunoincompetentes (12). A terapia antimicrobiana inicial foi empírica, para cobertura dos microrganismos Gram-positivos mais prevalentes nas infecções da tireoide, sendo posteriormente substituída conforme o resultado do antibiograma. Como consenso a escolha inicial do antibiótico deve basear-se principalmente na história clínica, nos fatores de risco do paciente e na gravidade do caso, optando-se, em geral, por derivados da penicilina com amplo espectro.

Muitas condições podem causar febre associada à dor na região anterior do pescoço exacerbada pela deglutição (traumas, abscessos parafaringeanos, infecções de cistos em ducto tireoglosso, ruptura de cistos ou hemorragias em nódulos tireoideos, crescimento rápido de câncer agressivo de tireoide, linfoma, trombose venosa, tireoidite granulomatosa subaguda e tireoidite linfocítica crônica), dificultando o reconhecimento da TA. Na avaliação inicial de um adulto com esses sintomas, é particularmente importante excluir os casos raros de tumores anaplásicos ou medulares com crescimento rápido associado a infarto, bem como a tireoidite granulomatosa subaguda (De Quervain), uma condição relativamente mais prevalente que também pode ser precedida por infecção do aparelho respiratório superior e que, no estágio doloroso, costuma apresentar-se clínica e laboratorialmente de forma semelhante à TA (7). O caso apresentado ilustra bem a dificuldade para se estabelecer esse diagnóstico diferencial. Até mesmo o ecoDoppler inicial desse paciente, ao demonstrar aumento difusamente heterogêneo do lobo direito, sem incremento de fluxo intraparenquimatoso e sem níveis líquidos, foi compatível com o diagnóstico de tireoidite De Quervain. Em casos como esse, a TC, a US seriada e a punção aspirativa com agulha fina representam importantes instrumentos para a identificação precoce de $\operatorname{abscessos}(7)$.

A maioria dos centros de tratamento elege a TC contrastada de pescoço e tórax como o melhor método de imagem para investigação da TA, entretanto, em pacientes sem compressão de vias aéreas, a US pode ser usada como primeira linha de investigação, possibilitando inclusive a imediata aspiração de conteúdos líquidos para diagnóstico etiológico e orientação terapêutica. A utilidade da ressonância magnética, PET-scan e cintigrafia com gálio para o diagnóstico de TA ainda não foi estabelecida e, como consenso, as cintigrafias com $\mathrm{I}^{123} \mathrm{ou} \mathrm{Tc}^{99 \mathrm{~m}}$ não oferecem vantagens já que não discriminam a TA, tireoidite subaguda e neoplasia maligna de tireoide (7).

$\mathrm{O}$ atraso no reconhecimento e consequentemente na abordagem terapêutica adequada provavelmente contribuiu para as complicações apresentadas pelo paciente, o que torna esse caso peculiar. Durante a evolução foram diagnosticados: tireotoxicose bioquímica, volumoso abscesso tireoidiano, compressão de traqueia e de grandes vasos, extensão do abscesso até o introito torácico, sepse e trombose de veia jugular interna.

Disfunções de tireoide e paratireoide foram descritas na TA, sendo a elevação transitória de tiroxina, decorrente da liberação de estoques hormonais pelo processo de destruição folicular, algumas vezes acompanhada de sinais clínicos de tireotoxicose, a alteração mais frequentemente verificada $(1,15)$.

A formação de abscessos intratireoideos ocorre em virtualmente todos os casos de TA $(10,16)$, mas suas 
complicações não têm prevalência estabelecida na literatura. Os abscessos podem destruir inteiramente tanto a tireoide quanto as paratireoides (originando deficiências hormonais permanentes), estender-se às estruturas adjacentes causando compressões, fístulas para esôfago e traqueia, paralisia de cordas vocais e tromboflebites (10). Além disso, pode ocorrer disseminação a distância com septicemia e morte.

Os grupos de Takai e Har-el (17) recomendam que qualquer indivíduo com TA de causa não estabelecida (especialmente se jovem ou com abscesso recorrente no lado esquerdo do pescoço) deva ser investigado para fístula congênita de seio piriforme enquanto Park e cols. (18) indicam a pesquisa apenas naqueles com recidiva de abscesso tireoideo ou paratireoideo. A TC, a radiografia contrastada com bário e a laringoscopia direta podem identificar a presença da comunicação anômala, devendo ser realizadas somente após o término da antibioticoterapia e resolução completa do processo infeccioso/inflamatório, o qual pode obliterar temporariamente o trajeto da fístula. No caso de fístulas congênitas ou adquiridas como complicação do abscesso, a cirurgia reparadora ou cauterização é essencial para prevenir infecções recorrentes.

A formação de trombos simples ou sépticos em veias jugulares internas é uma complicação grave vinculada às infecções de pescoço e trato aerodigestivo superior que pode resultar da estase venosa (oclusão pelo processo inflamatório), hipercoagulabilidade sistêmica e lesão endotelial direta causada pelos microrganismos e/ou lesão inflamatória perivascular. $\mathrm{Na}$ trombose infectada, a drenagem do abscesso local associada à antibioticoterapia por até seis semanas é o tratamento de escolha. O papel da anticoagulação sistêmica no tratamento da trombose infectada não foi inteiramente estabelecido, porém, como consenso, a medida deve ser sempre considerada quando houver suspeita de embolização (19).

Em síntese, esse caso raro reforça a necessidade de atenção ao diagnóstico da TA e também a relevância da imediata instituição do tratamento, visando à prevenção de graves complicações relacionadas à desordem, muitas delas potencialmente letais.

Declaração: os autores declaram não haver conflitos de interesse científico neste estudo.

\section{REFERÊNCIAS}

1. Sicilia V, Mezitis S. A case of acute suppurative thyroiditis complicated by thyrotoxicosis. J Endocrinol Invest. 2006;29(11):9971000.

2. Giadrosich RV, Hernández MIC, Izquierdo $\mathrm{CQ}$, Zamora BK. Tiroiditis aguda supurada en un paciente pediátrico. Rev Med Chil. 2004;132(2):219-22.

3. Torres MRS, Medeiros CCM, Nobrega Neto SH, Souza LS, Rodrigues MLC, Silva MNM, et al. Forma atípica de tireoidite supurativa aguda em paciente pediátrico: relato de caso. Arq Bras Endocrinol Metab. 2008;52(4):701-6.

4. Yoshino $Y$, Inamo Y, Fuchigami T, Hashimoto K, Ishikawa T, Abe O, et al. A pediatric patient with acute suppurative thyroiditis caused by Eikenella corrodens. J Infect Chemother. 2010;16:353-5.

5. Suprabha J, Vijay K, Shital P. Acute bacterial thyroid abscess as a complication of septicemia. IDCP. 2000;9:383-6.

6. Brook I. Microbiology and management of acute suppurative thyroiditis in children. Int $\mathrm{J}$ Pediatr Otorhinolaryngol. 2003;67(5):447-51.

7. Paes JE, Burman KD, Cohen J, Franklyn J, McHenry CR, Shoham $S$, et al. Acute bacterial suppurative thyroiditis: a clinical review and expert opinion. Thyroid. 2010;20:247-55.

8. Werner SC, Ingbar SH, Braverman LE, Utiger RD. Werner \& Ingbar's the thyroid: a fundamental and clinical text. 8.ed. Philadelphia: Lippincott Williams \& Wilkins, 2000.

9. Ilyin A, Zhelonkina N, Severskaya N, Romanko S. Nonsurgical management of thyroid abscess with sonographically guided fine needle aspiration. J Clin Ultrasound. 2007;35:333-7.

10. Al-Dajani N, Wootton SH. Cervical lymphadenitis, suppurative parotitis, thyroiditis, and infected cysts. Infect Dis Clin North Am. 2007;21:523-41, viii.

11. Bertelli AAT, Andrade SJC, Kavabata NK, Menezes MB, Gonçalves AJ. Abscesso de tireoide tratado por punção: relato de caso e revisão de literatura. Rev Bras Cir Cabeça e Pescoço. 2005;34(2):23-6.

12. Jacobs A, Gros DAC, Gradon JD. Thyroid abscess due to Acinetobacter calcoaceticus: case report and review of the causes of and current management strategies for thyroid abscesses. South Med J. 2003;96(3):300-7.

13. Seki $N$, Himi T. Retrospective review of 13 cases of pyriform sinus fistula. Am J Otolaryngol. 2007;28:55-8.

14. Slatosky J, Shipton B, Wahba H. Thyroiditis: differential diagnosis and management. Am Fam Physician. 2000;61:1047-54.

15. Nishihara E, Ohye H, Amino N, Takata K, Arishima T, Kudo T, et al. Clinical characteristics of 852 patients with subacute thyroiditis before treatment. Inter Med. 2008;47:725-9.

16. Schneider U, Birnbacher R, Schick S, Ponhold W, Schober E. Recurrent suppurative thyroiditis due to pyriform sinus fistula. Eur J Pediatr. 1995;154:640-2.

17. Park BW, Park CS. Pyriform sinus fistula. Yonsei Med J. 1993;34(4):386-90.

18. Park SY, Kim EK, Kim MJ, Kim BM, Oh KK, Hong SW, et al. Ultrasonographic characteristics of subacute granulomatous thyroiditis. Korean J Radiol. 2006;7:229-34.

19. Jonas NE, Fagan JJ. Internal jugular vein thrombosis: a case study and review of the literature. Internet $\mathrm{J}$ Otorhinolaryngol. 2007;6:2. 